\title{
VARIASI BAHASA MINANGKABAU DIALEK MASYARAKAT KENAGARIAN KOTO BANGUN DENGAN DIALEK MASYARAKAT KENAGARIAN MUARO PAITI KECAMATAN KAPUR IX KABUPATEN LIMA PULUH KOTA PROVINSI SUMATERA BARAT
}

\author{
Lili Hasmi
}

STKIP Yayasan Abdi Pendidikan Payakumbuh

\begin{abstract}
ABSTRACK
Variations in the Minangkabau Language of the Koto Bangun Kenagarian Community Dialect with the Muaro Paiti Kenagarian Community Dialect in the Lima Puluh Kota

Research is motivated by differences in dialects between regions. The purpose of this research is to describe variations of the Minangkabau dialect in terms of phonology based on phonemic. The dialect studied was the Koto Bangun Kenagarian Community Dialect with the Muaro Paiti Kenagarian Community Dialect Kapur IX District Lima Puluh Kota. This type of qualitative research with the description method. The object of research is the Kagagarian Kenagarian community with the Muaro Paiti Kenagarian Society, Lima Puluh Kota. Research data were collected by interview, note taking and record techniques. After the data is collected, it is then analyzed using the intra lingual matching method.

The results showed three things: (1) Of the 200 vocabularies, there are 155 phonemic equations forming vocabulary. (3) Of 200 vocabulary 52 variations of phonemic vocabulary. (2) Of the 200 vocabulary words, there are 200 terms in which the basic terms of the vocabulary aspect of the purpose of saying something. It can be concluded that of the 200 vocabularies studied, only 52 vocabularies have phonemic variations of word formers. So, the variation of language is the reality of language that must be recognized. The language variation must always be maintained by the community he said. So that the language they use is not lost in line with the times.
\end{abstract}

Key Word : (Variasi, Dialek, Masyarakat.)

\begin{abstract}
ABSTRAK
Variasi Bahasa Minangkabau Dialek Komunitas Koto Bangun Kenagarian dengan Dialek Komunitas Muaro Paiti Kenagarian di Lima Puluh Kota

Penelitian dilatarbelakangi oleh perbedaan dialek antar daerah. Tujuan penelitian ini adalah mendeskripsikan variasi dialek Minangkabau ditinjau dari fonologi berdasarkan fonemik. Dialek yang dipelajari adalah Dialek Komunitas Koto Bangun Kenagarian dengan Dialek Komunitas Muaro Paiti Kenagarian Kapur IX Distrik Lima Puluh Kota. Jenis penelitian kualitatif dengan metode deskriptif. Objek penelitian adalah komunitas Kenagarian Kagagarian dengan Masyarakat Kenagarian Muaro Paiti Lima Puluh Kota. Data penelitian dikumpulkan dengan teknik wawancara, pencatatan dan pencatatan. Setelah data terkumpul kemudian dianalisis menggunakan metode pencocokan intra lingual.

Hasil penelitian menunjukkan tiga hal: (1) Dari 200 kosakata, terdapat 155 persamaan fonemik pembentuk kosakata. (3) Dari 200 kosakata 52 variasi
\end{abstract}


kosakata fonemik. (2) Dari 200 kosakata, terdapat 200 istilah yang merupakan kosakata istilah dasar yang digunakan untuk tujuan mengatakan sesuatu. Dapat disimpulkan bahwa dari 200 kosakata yang dipelajari, hanya 52 kosakata yang memiliki variasi fonemik pembentuk kata. Jadi, variasi bahasa merupakan realitas bahasa yang harus dikenali. Variasi bahasa harus selalu dijaga oleh masyarakat, ujarnya. Agar bahasa yang mereka gunakan tidak hilang seiring dengan perkembangan zaman.

Kata Kunci: (Variasi, Dialek, Masyarakat.)

\section{PENDAHULUAN}

Bahasa merupakan lambang bunyi yang bersifat arbitrer. Disebut arbitrer karena bahasa itu bersifat mana suka. Dalam kehidupan sehari-hari, bahasa digunakan sebagai alat komunikasi. Bahasa sebagai alat komunikasi antara seseorang dengan orang lain memiliki banyak variasi. Pada umumnya bahasa daerah yang satu dengan yang lainnya terdapat perbedaan, yang biasa disebut dengan variasi dialek.

Variasi penggunaan dialek yang berlainan daerah tidak menjadikan suatu masyarakat terpisah atau terkucilkan oleh masyarakat lainnya. Di antara banyaknya variasi bahasa yang ada, yang menyebabkan perbedaan dialek antara daerah karena adanya variasi geografis. Variasi geografis disebabkan oleh perbedaan geografis antar daerah, secara tidak langsung bahasa yang digunakan oleh setiap daerah pun berbeda pula. Daerah yang memiliki geografi yang berbeda adalah daerah Koto Bangun dengan daerah Muaro Paiti.

Fonetik dan fonemik keduanya termasuk bidang fonologi. Fonetik menitik beratkan analisisnya pada masalah bunyi-bunyi bahasa tanpa menghiraukan fungsi masing-masing bunyi. tersebut dalam ucapan. Fonemik berusaha menganalisis bunyi-bunyi yang berperan sebagai pembela makna. Bunyi-bunyi tersebut dalam ilmu bahasa disebut fonem. Berdasarkan di mana beradanya bunyi bahasa itu "sewaktu dikaji, dibedakan adanya tiga macam fonetik. yaitu fonetik artikulatoris, fonetik akustik dan, fonetik auditoris.

Penelitian bahasa daerah merupakan salah satu kegiatan yang dilaksanakan untuk memelihara dan mengembangkan bahasa daerah. Kegiatan ini akan bermanfaat untuk perkembangan bahasa Indonesia, karena bahasa daerah sangat berperan dalam memperkaya khasnya kebudayaan dan identitas nasional.

Tabel 1. Perbedaan dialek antara Kenagarian Koto Bangun dengan Kenagarian Muaro Paiti dapat dilihat dari beberapa contoh dibawah ini :

\begin{tabular}{|c|c|c|c|}
\hline No & $\begin{array}{c}\text { Kosa Kata Bahasa } \\
\text { Indonesia }\end{array}$ & $\begin{array}{c}\text { Kosa Kata Bahasa } \\
\text { Koto Bangun }\end{array}$ & $\begin{array}{c}\text { Kosa Kata Bahasa } \\
\text { Muaro Paiti }\end{array}$ \\
\hline 1. & Air & Ayiu & Ayigh \\
2. & Antar & Antau & Antagh \\
3. & Basah & Babiak & Babiyak \\
4. & Dengar & Dongau & Dongaw \\
5. & Kiri & Kido & Kida \\
\hline
\end{tabular}

Kosa kata di atas adalah beberapa contoh dari Variasi Bahasa Minangkabau Dialek Kenagarian Koto Bangun dengan Kenagarian Muaro Paiti Kecamatan Kapur IX Kabupaten Lima Puluh Kota.

Fokus masalah pada penelitian ini adalah Variasi Bahasa Minangkabau. Rumusan masalah. Apakah terdapat Variasi Bahasa Minangkabau? Tujuan 
penelitian mendeskripsikan Variasi Bahasa Minangkabau Dialek Kenegarian Koto Bangun dengan Kenagarian Muaro Paiti Kecamatan Kapur IX Kabupaten Lima Puluh Kota dari segi fonologi berdasarkan fonemik. Penelitian ini diharapkan dapat memiliki manfaat, baik secara teoritis maupun secara praktis.

Setiap masyarakat di Indonesia mempunyai bahasa yang berbeda-beda, karena bahasa itu bersifat mana suka, sehubungan dengan hal tersebut, Chaer (2006: 1) menjelaskan bahwa "Bahasa adalah suatu sistem lambang barupa bunyi, bersifat arbitrer, digunakan oleh suatu masyarakat tutur untuk bekerja sama, berkomunikasi, dan mengidentifikasi diri.

Secara umum bahasa berfungsi sebagai alat komunikasi lisan maupun fisik. Oleh karena itu, bahasa memounyai fungsi yang penting bagi kelangsungan hidup bermasyarakat. Menurut Soeparno (2003:5) "Fungsi umum bahasa adalah sebaagai alat komunikasi sosial." Di dalam hidup bermasyarakat, mereka mereka saling berinteraksi dan saling berkomunikasi dengan menggunakan bahasa. Hal tersebut juga dikemukakan oleh Rahardi (2008:6), bahwa " fungsi bahasa yang paling utama adalah fungsi komunikasi dan interaksi.

Variasi bahasa adalah penggunaan bahasa menurut pemakainya, yang berbeda-beda menurut topik yang dibicarakan, menurut hubungan pembicara, kawan bicara, dan orang yang dibicarakan serta menurut medium pembicaraan. Sebuah bahasa mempunyai sistem dan subsistem yang dipahami sama oleh sama penutur bahasa tersebut. Namun, karena penutur bahasa tersebut, meski berada dalam masyarakat tutur, tidak merupakan kumpulan manusia homogen, wujud bahasa yang konkret, yang disebut parole, menjadi tidak seragam atau bervariasi. Terjadinya keragaman atau kevariasian bahasa ini bukan hanya disebabkan oleh para penuturnya yang tidak homogen, tetapi juga kegiatan interaksi sosial yang mereka lakukan sangat beragam (Chaer dan Agustina, 2010: 61).

Istilah fonologi berasal dari phonology, yaitu gabungan kata phon dan logy (Arifin, 1989:2). Kata phone berarti bunyi bahasa, baik itu bunyi vokal maupun bunyi konsonan, Sedangkan logy berarti ilmu pengetahuan. Menurut Chaer (2003:102) fonologi adalah "Bidang linguistik yang mempelajari, menganalisis, dan membicarakan runtunan bunyi-bunyi bahasa."

Fonemik sebagai bahagian fonologi berusaha membicarakan bunyi-bunyi bahasa yang berperan sebagai pembeda makna kata (Arifin, 1989:5). Sehubungan dengan itu Chaer (2003:125) mengatakan bahwa dalam fonemik kita meneliti apakah perbedaan bunyi itu mempunyai fungsi sabagai pembeda makna atau tidak. Lebih lanjut Abas (dalam Arifin, 1989:5) menjelaskan bahwa tujuan analisis bunyi-bunyi bahasa secara fonemik ini ialah untuk mencari sistem ejaan berdasrkan fonem-fonem yang ada dalam bahasa yang bersangkutan.

\section{METODOLOGI}

Jenis penelitian yang digunakan adalah penelitian kualitatif dengan metode deskriptif. Menurut Moleong (2005:6) menjelaskan bahwa penelitian kualitatif merupakan penelitian yang bermaksud untuk memahami fenomena yang dialami oleh subjek penelitian. Menurut Moleong (2005:4), pendekatan deskriptif kualitatif yaitu pendekatan penelitian dimana data-data yang dikumpulkan berupa katakata, gambar-gambar dan bukan angka. Data-data tersebut dapat diperoleh dari hasil wawancara, catatan lapangan, foto, video tape, dokumentasi pribadi, catatan, atau memo dan dokumentasi lainnya. 
Objek penelitian adalah masyarakat Kenagarian Koto Bangun dan Kenagarian Muaro Paiti Kapur IX. Kapur IX adalah sebuah kecamatan di Kabupaten Lima Puluh Kota, Sumatera Barat, Indonesia. Pemilihan dua daerah ini sebagai sumber penelitian disebabkan karena dalam penggunaan bahasa seharihari memiliki perbedaan. Hal ini terjadi pada bahasa yang sama. Penelitian ini dilakukan di Kenegarian Koto Bangun dengan Kenagarian Muaro Paiti Kecamatan Kapur IX Kabupaten Lima Puluh Kota dari segi fonologi berdasarkan fonemik.

Informan adalah orang yang akan memberikan data penelitian. Informan akan memberikan informasi kebahasaan yang dicari oleh peneliti. Tanpa informan, penelitian tidak dapat dilakukan. Sehubungan dengan itu, Mahsun (2005:30) mengemukakan bahwa informan adalah "Sampel penutur atau orang yang ditentukan di wilayah pakai varian bahasa tertentu sebagai narasumber bahan penelitian, pemberi informasi, dan pembantu peneliti dalam tahap penyediaan dataBerdasarkan pendapat di atas, maka peneliti mengambil informan dalam penelitian ini sebanyak 6 orang. Tiga orang dari masyarakat Kenagarian Koto Bangun dan tiga orang dari masyarakat Kenagarian Muaro Paiti. Informan yang ditetapkan harus yang sesuai dengan kriteria yang telah ditetapkan. Menurut Mahsun (2005:41) menyatakan bahwa dalam memilih informan penelitian, sebaiknya harus memenuhi beberapa persyaratan-persyarat, yaitu (1) kelamin pria atau wanita, (2) berusia antara 25-65 tahun (tidak pikun), (3) orang tua, istri, atau suami informan lahir dan dibesarkan di desa itu serta jarang atau tidak pernah meninggalkan desanya, (4) berpendidikan minimall tamat pendidikan dasar (SDSLTP), (5) berstatus sosial menengah (tidak rendah atau tidak tinggi) dengan harapan tidak terlalu tinggi mobilitasnya, (6) pekerjaannya bertani atau buruh, (7) memiliki kebangsaan terhadap isoleknya, (8) dapat berbahasa Indonesia, dan (9) sehat jasmani dan rohani.

Informan dalam penelitian ini adalah masyarakat yang bertempat di Kenagarian Koto Bangun dan di Kenagarian Muaro Paiti yang didasarkan pada persyaratan di atas. Penulis akan meneliti sebanyak enam orang informan, di antaranya tiga orang Masyarakat dari Kenagarian Koto Bangun dan tiga orang dari Masyarakat Kenagarian Muaro Paiti Kapur IX Kecamatan Kapur IX Kabupaten Lima Puluh Kota.

Instrumen utama dalam penelitian ini adalah penelitian sendiri, dan dilengkapi dengan alat perekam (tape recorder), lembaran pengamatan yang digunakan untuk mencatat tuturan masyarakat tersebut, serta lembaran wawancara. Moleong, (2010:189). Pengumpulan data dalam penelitian ini dilakukaaan dengan menggunakan metode simak dan metode cakap (wawancara) yaitu percakapan antara peneliti dengan informan yang telah dipilih. Percakapan yang dilakukan menggunakan wawancara terbuka yaitu wawancra yang dengan memberi tahu informan bahwa mereka sedang di wawancarai dan mengetahui pula apa maksud dan tujuan wawancara itu wawancara ini dilakukan secara terstruktur.

Berdasarkan uraian di atas, maka langkah-langkah yang peneliti lakukan dalam pengumpulan data adalah sebagai berikut ini.

1. Membuat daftar urutan pertanyaan yang akan diajukan kepada informan sesuai dengan masalah yang akan diteliti. 
2. Peneliti langsung turun ke lapangan untuk mewancarai informan yang sudah ditetapkan berdasarkan kriteria tertentu.

3. Setelah sampai di lapangan, peneliti langsung berdialog dengan informan.

4. Selanjutnya, sambil melakukan wawancara dengan informan, peneliti langsung merekam dan mencatat data-data yang relevan dengan data penelitian.

Adapun peralatan yang peneliti pakai dalam melangsungkan penelitian ini adalah (1) pena, (2) buku, dan (3) alat rekam. Pena digunakan untuk mencatat kosa kata yang diucapkan oleh informan. Buku digunakan sebagai tempat mencatat data penelitian, sedangkan alat rekam digunakan untuk merekam dalam proses wawancara.

Data yang diperoleh tersebut dianalisis dengan menggunakan metode padan instraingual. Metode padan intralingual adalah metode analisis dengan cara menghubung-bandingkan unsur-unsur yang bersifat lingual, baik yang terdapat dalam satu bahasa maupun dalam beberapa bahasa yang berbeda" (Mahsun, 2007:118). Metode padan intralingual memiliki 3 teknik analisis data, yaitu (1) teknik hubungbanding menyamakan (HBS), (2) teknik hubung-banding membedakan (BBB), dan (3) teknik hubung-banding menyamakan hal pokok (HBSP). Teknik ini, bertujuan untuk mencari kesamaan hal pokok dari pembedaan dan penyamaan yang dilakukan. Dan tujuan akhir dari banding menyamakan atau membedakan tersebut adalah menemukan kesamaan pokok di antara data yang diperbandingkan itu. Untuk lebih jelasnya, berikut ini akan diuraikan langkahlangkah dalam penganalisaan data penelitian.

1. Setelah data yang didapatkan relevan dengan masalah yang akan diteliti, peneliti memasukkan kedalam bentuk tabel.

2. Menghubung-hubungkan dan membanding-bandingkan data guna mencari persamaan data dari kedua Kenagarian.

3. Menghubung-hubungkan dan membanding-bandingkan guna mencari perbedaan data dari kedua Kenagarian.

4. Menghubung-hubungkan dan membanding-bandingkan hal pokok guna mencari perbedaan data dari kedua Kenagarian.

5. Mengklasitikasikan kata-kata tersebut ke dalam bentukjenis katanya.

6. Terakhir, membahas hasil analisis dan membuat simpulan.

Teknik pengabsahan data dalam penelitian ini menggunakan teknik triangulasi. Moleong (2005:330) menyatakan triangulasi berarti cara terbaik untuk menghilangkan perbedaan-perbedaan kenyataan yang ada, dalam konteks suatu studi sewaktu mengumpulkan data tentang berbagai kejadian dan hubungan sebagai pandangan. Teknik pengabsahan data yang digunakan pada penelitian adalah triangulasi sumber. Sumber pengujian data penelitian ini adalah dosen pembimbing atau yang ahli dalam bidang fonologi. Peneliti meminta kesediaan dosen pembimbing sebagai nara sumber dikarenakan data-data yang telah terkumpul merupakan persetujuan dan kesepakatan dari dosen pembimbing. Melalui pengabsahan ini, maka data-data dalam peneltian ini akan falid dan dapat dipertanggung jawabkan.

\section{HASIL PENELITIAN DAN PEMBAHASAN}

Berdasarkan teknik analisis data, maka analisis data menggunakan teknik hubung banding menyamakan (HBS). Hubung-banding dalam penelitian ini 
adalah kosa kata yang diucapkan oleh para informan, terdiri dari 200 kata dasar (Tabel 4). Tujuan hubung banding menyamakan ini adalah untuk menemukan kesamaan fonem antara data yang dibandingkan itu dengan yang lainya. Berikut adalah tabel hubung-banding menyamakan variasi bahasa Minangkabau oleh masyarakat Kenagarian Koto Bangun dengan Masyarakat Kenagarian Muaro Paiti.

Berdasarkan analisis data, terdapat 155 buah kosa kata yang memiliki persamaan fonem pembentuknya. Berikut adalah beberapa penjabaran kosa kata yang memiliki persamaan fonem pembentuk kosa kata. Kata yang memiliki persamaan fonem pembentuknya. Kata tersebut adalah kata api oleh masyarakata kenagarian KotoBangun adalah [api], dan oleh masyarakat Muaro Paiti adalah [api]. Persamaan fonem pembentuk kedua kata tersebut adalah [A], [p], [i]. Kata $a b u$ oleh masyarakat Koto Bangun adalah $[a b u]$, dan oleh masyarakat Muaro Paiti adalah $[a b u]$. Persamaan fonem pembentuk kedua kata tersebut adalah $[\mathrm{a}],[\mathrm{b}]$, [u]. Kata Apa oleh masyarakat Koto Bangun adalah [ApO], dan oleh masyarakat Muaro Paiti adalah $[A p O]$. Persamaan fonem pembentuk kedua kata tersebut adalah [a], [p], [O]. Kata Aku oleh masyarakat Koto Bangun adalah [den], dan oleh masyarakat Muaro Paiti adalah [den]. Persamaan fonem pembentuk kedua kata tersebut adalah [d] ,[e], [n]. Kata Anak angin oleh masyarakat Koto Bangun adalah [ana?] dan oleh masyarakat Muaro Paiti adalah [ana?] . Persamaan fonem pembentuk kedua kata tersebut adalah [a], [n], [a],[?].

Berdasarkan teknik analisis data, maka analisis data menggunakan teknik hubung-banding membedakan (HBB). Yang di hubung-bandingkan dalam peneltian ini adalah kosa kata yang diucapkan oleh informan, terdiri dari 200 kata dasar (Tabel 4). Tujuan hubung banding membedakan ini adalah untuk menemukan perbedaan fonem antara data yang di bandingkan. Berikut ini adalah tabel hubung-banding membedakan variasi bahasa Minangkabau oleh masyarakat Kenagarian Koto Bangun dengan masyarakat Kenagarian Muaro Paiti.

Berdasarkan tabel analisis data, terdapat 52 kosa kata yang memliki perbedaan fonem pembentuknya. Berikut adalah beberapa penjabaran kosa kata yang memiliki perbedaan fonem pembentuk kosa kata. Kata yang memiliki perbedaan fonem pembentuknya adalah kata air oleh masyarakat kenagarian Koto Bangun adalah [ayiu] ( dibnetuk oleh fonem [a], [y], [i], [u]) dan oleh masyarakat kenagarian Muaro Paiti adalah [ayiY] (dibentuk oleh fonem [a], [y], [i], [Y]). Perbedaan fonem dalam kedua kata tersebut adalah fonem [u] dengan fonem [Y]. Kata akar oleh masyarakat kenagarian Koto Bangun adalah [akau] ( dibnetuk oleh fonem $[a],[k],[a],[u])$ dan oleh masyarakat kenagarian Muaro Paiti adalah $[a k a \gamma]$ (dibentuk oleh fonem [a], [k], [a], [Y]). Perbedaan fonem dalam kedua kata tersebut adalah fonem [u] dengan fonem [Y]. Kata abah oleh masyarakat kenagarian Koto Bangun adalah [ayah] ( dibnetuk oleh fonem [a], $[y],[a],[h]$ ) dan oleh masyarakat kenagarian Muaro Paiti adalah [aya] (dibentuk oleh fonem $[a],[y],[a])$. Perbedaan fonem dalam kedua kata tersebut adalah penambahan fonem [h] pada masyarakat kenegarian Koto Bangun.

Berdasarkan teknik analisis data, maka analisis data menggunakan teknik hubung-banding membedakan (HBB). Yang di hubung-bandingkan hal dalam peneltian adalah kosa kata yang diucapkan oleh informan, terdiri dari 200 kata dasar (Tabel 4). Tujuan hubung banding menyamakan hal pokok ini adalah untuk menemukan kesamaan hal pokok atau makna antara data yang dibandingkan. 
Berikut ini adalah tabel hubung-banding menyamakan hal pokok variasi bahasa Minangkabau oleh masyarakat Kenagarian Koto Bangun dengan masyarakat Kenagarian Muaro Paiti.

Berdasarkan tabel di atas, terdapat 200 buah kosa kata yang mempunyai persamaan hal pokok atau maknanya. Berikut adalah beberapa penjabaran kosa kata yang memiliki persamaan hal pokok pembentuk kosa kata . Adapun kata tersebut adalah Kata abang oleh masyarakat Kenagarian Koto Bangun disebut dengan [abang] dan oleh masyarakat Kenagarian Muaro Paiti disebut dengan [abang], kedua kata tersebut memiliki hal pokok yang sama yaitu untuk mengatakan kata abang. Kata $a b u$ oleh masyarakat Kenagarian Koto Bangun disebut dengan $[a b u]$ dan oleh masyarakat Kenagarian Muaro Paiti disebut dengan $[a b u]$, kedua kata tersebut memiliki hal pokok yang sama yaitu untuk mengatakan kata $a b u$. Kata adik oleh masyarakat Kenagarian Koto Bangun disebut dengan [adiak] dan oleh masyarakat Kenagarian Muaro Paiti disebut dengan [adiak], kedua kata tersebut memiliki hal pokok yang sama yaitu untuk mengatakan kata adik.

\section{PEMBAHASAN}

Berdasarkan analisis data di atas, maka dalam pembahasan ini akan dibahas tiga hal, yaitu (1) hubung-banding menyamakan data penelitian, (2) hubung-banding membedakan data penelitian, dan (3) hubung banding menyamakan hal pokok data penelitian. Berikut ini akan diuraikan mengenai ketiga hal tersebut.

Berdasarkan analisis teknik hubung-banding menyamakan data penelitian di atas, berikut ini akan dibahas mengenai persamaan fonem pembentuk kosa kata antara dialek masyarkat Kenagarian Koto Bangun dengan masyarakat Kenagarian Muaro Paiti. Dari 200 buah kosa kata, terdapat 155 buah kosa kata yang memiliki persamaan fonem. Contoh kosa kata yang memiliki persamaan fonem sebagai berikut ini.

Berdasarkan analisis teknik hubung banding membedakan data penelitian di atas, berikut ini akan dibahasn mengenai perbedaan fonem pembentuk kosa kata antara dialek masyarakat kenagarian Koto Bangun dengan dialek masyarkat kenagarian Muaro Paiti. Dari 200 kosa kata, terdapat 52 kosa kata yang memiliki perbedaan fonem. Berikut contoh kosa kata yang memiliki variasi fonemik.

Berdasrakan analisis teknik hubung banding menyamakan hal pokok atau makna kosa kata antara dialek masyarakat kenagarian Kotobangun dengan dielek masyarakat kenagarian Muaro Paiti. Dari 200 kosa kata. Kesemua kosa kata tersebut memiliki persamanaan hal pokok atau tujuan untuk mengatkan sesuatu. Berikut contoh kosa kata yang memliki persamaan hal pokok.

\section{KESIMPULAN DAN SARAN}

\section{Kesimpulan}

Berdasarkan deskripsi data, analisis data, dan pembahasan yang mengacu pada bab I, bab II, dan bab III, dapat disimpulkan :

1. Dari 200 kosa kata yang diteliti, terdapat 155 persamaan fonem pembentuk kosa kata. Hasil ini disimpilkan setelah melakukan analisis hubung banding menyamakan data penelitian. 
2. Dari 200 kosa kata yang diteliti, terdapat 52 variasi kosa kata fonemik. Hasil ini disimpulkan setelah melakukan analisis hubung banding membedakan data penelitian.

3. Dari 200 kosa kata yang diteliti, terdapat 200 persamaan hal pokok kosa kata dari aspek tujuan untuk mengatakan sesuatu. Hasil ini disimpulkan setelah melakukan analisis hubung banding menyamakan hal pokok data penelitian.

\section{Saran}

Berdasarkan hasil penelitian dan kesimpulan tersebut, penulis menyarankan:

1. Dengan adanya perbedaan bahasa tersebut, kedua daerah hendaknya tidak saling menjatuhkan dan kedua daerah tersebut tidak memiliki perbedaan ke arah yang kurang baik.

2. Penelitian ini hanya terfokus pada linguistik dari segi fonologi, hendaknya dapat dilanjutkan pada daerah dan pada cakupan yang lebih luas.

3. Agar penelitian ini dapat bermanfaat dan jadi pedoman bagi penelitian selanjutnya.

4. Ini merupakan kenyataan bahasa yang harus kita akui kebeneranya di tengahtengah masyarakat pemakai bahasa.

5. Untuk pengguna bahasa agar bisa mempertahan keaslian bahasa yang dimiliki masing-masing jangan sampai hilang oleh seiring perkembangan zaman.

6. Untuk pengguna bahasa jangan malu-malu memakai bahasa yang sudah menjadi bahasa masyarakat asli daerah kita, karena bahasa itu bersifat manasuka atau aebitrer.

7. Mudah-mudahan penelitian bahasa dialek minangkabau dimasa-masa yang akan datang lebih mendalam dan lebih maju lagi, agar bahasa minangkabau mudah dikenali oleh masyarakat lain.

\section{DAFTAR PUSTAKA}

Chaer, Abdul. 2006. Tata Bahasa Praktis Bahasa Indonesia. Jakarta: Rineka Cipta.

Chaer, Abdul. 2003. Linguistik Umum. Jakarta: Rineka Cipta.

Chaer, Abdul dan Leoni Agustina. Sosiolinguistik: Perkenalan Awal. Jakarta: Rineka Cipta.

Hadi, Faisal. 2011. Variasi Bahasa Dialek Minangkabau Antara Masyarakat Kenagarian Pasieh Laweh Dengan Masyarakat Kenagarian Pauh Gadih Kecamatan Palupuh Kabupaten Agam. Skripsi. Padang UNP Press.

Ijang, 2013 Variasi Bahasa Minangkabau Dialek Masyarakat Kenagarian Tanjung

Bonai Kabupaen Tanah Datar Dengan Dialek Masyarakat Kenagarian Ampalu Kabupaten Lima Puluh Kota. Skripsi. Payakumbuh: STKIP Abdi Pendidikan.

Mahsun. 2007. Metode Penelitian Bahasa: Tahapan Strategi, Metode, dan Tekniknya. Jakarta: Raja Grafindo Persada.

Moleong. 2005. Metode Penelitian Kualitatif. Bandung: Remaja Rosda Karya.

Rahardi, Kunjana, 2008. Bahasa Indonesia Perguruan Tinggi. Jakarta: Erlangga.

Regika. 2010. Keseragaman Pemakaian Kata Sapaan Bahas Minangkabau 
Dikenagarian Andaleh Kecamatan Andaleh Kabupaten Tanah Datar. Skripsi. Padang: UNP Press.

Soeparno. 2003. Dasar-dasar Linguistik. Yogyakarta: Mitra Gama Widya. 